\section{A clarividência das resenhas:}

\section{Borges}

B ORIS SCHNAIDERMAN

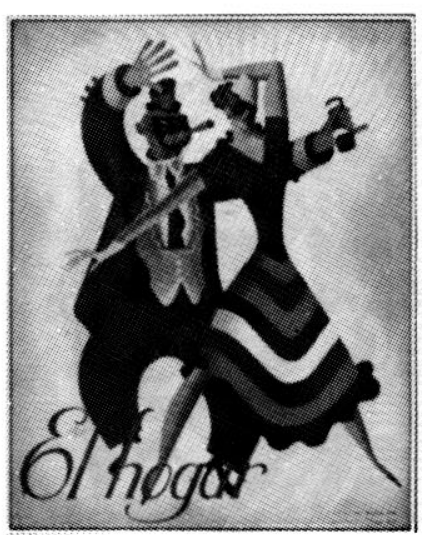

A revista semanal argentina $\mathrm{El} \mathrm{Hogar}$ circulou um pouco no Brasil nas décadas de 1930 e 40. Dirigindo-se essencialmente a um público feminino, tinha as seções habituais deste tipo de publicação e também, a par de contos originais e traduzidos e resenhas de livros em espanhol, a seção "Libros y autores extranjeros", que esteve a cargo de Jorge Luis Borges entre 1936 e 39. Suas páginas podem ser lidas agora no livro póstumo de Borges, Textos Cautivos - Ensayos y Reseñas en "El Hogar", organizado por Emir Rodríguez Monegal e seu discípulo e colaborador, Enrique Sacerio-Garí. Este narra num comovido prólogo as longas caminhadas a pé, que ambos realizaram através de toda New Haven, quando discutiram a possibilidade deste livro, e as leituras e releituras em casa de Emir, no ano que precedeu a morte deste, em 1985.

Se a idéia inicial do livro se deve a Monegal, que provavelmente contribuiu também para a sua organização, a execução do trabalho tem de ser creditada a Sacerio-Garí, que o realizou com toda a seriedade e muito encantamento. Encantamento sem o qual, certamente, toda aproximação desta obra se torna precária.

É indispensável afirmar que ela dá uma grande lição a todos nós que praticamos o jornalismo literário. Defrontando-se com a tarefa de manter uma seção, cuja forma já estava determinada e que fora mantida por outros colaboradores, Borges imediatamente lhe imprimiu características muito peculiares. Se a linguagem é sempre bastante singela, direta, e muitas vezes incisiva, cortante, ao mesmo tempo não se encontra ali nenhuma concessão ao gosto do público médio. Parece até haver um acordo tácito entre o escritor e a direção da revista: você nos dá sua prosa cristalina, a sua erudição fabulosa, e nós não interferimos nos seus textos. Impressionante como eles nos dizem muito até hoje. $\mathrm{Na}$ verdade, o escritor subverte a delimitação, tantas vezes estabelecida rigidamente, entre jornalismo, literatura e erudição.

A seção tinha quatro divisões: ensaios, resenhas, biografias sintéticas e notas sobre a vida literária.

As resenhas são de tipo bem diferente daquelas com que nos acostumamos em nossa imprensa e mostram que essa modalidade de texto pode atingir um nível tão alto de realização. Ao contrário do que geralmente acontece até hoje, elas quase não contêm resumos ou paráfrases. Às vezes, Borges até faz charme com o leitor ávido de resumos. Assim, a propósito do romance policial The Beast Must Die, de Eden Phillpotts, escreve: "...me parece admirable. Me abstengo de contar su argumento, porque prefiero que el curioso lector la pida prestada o la robe o hasta la compre. Le prometo que no se arrepentira". Geralmente, o livro a ser resenhado é objeto de uns poucos flashes, destinados a captar o essencial. E, nos casos em que alguns trechos lhe interessam mais vivamente, o autor se permite simplesmente copiá-los. O que está perfeitamente de acordo com uma característica de sua escrita, captada por Sacerio-Garí em sua introdução: "Para Borges, la literatura se hace selecionando de otros textos".

As "biografias sintéticas" são construídas com uns poucos dados sobre cada autor e com uma apreciação bem sumária sobre sua obra. Mas este sumário é sempre bem penetrante. Para que se compreenda a posição de Borges em relação a este problema, con-
BORIS SCHNAIDERMAN é professor aposentado do curso de Russo do Departamento de Línguas Orientais da FFLCH-USP, tradutor e ensaísta. É autor de Turbilhão e Semente (Editora Duas Cidades) e Dostoiévski - Poesia e Prosa (Editora Perspectiva).

Textos Cautivos - Ensayos y Reseñas en "El Hogar", Jorge Luis Borges, Barcelona, Tusqueto Editores, 338 pp. 


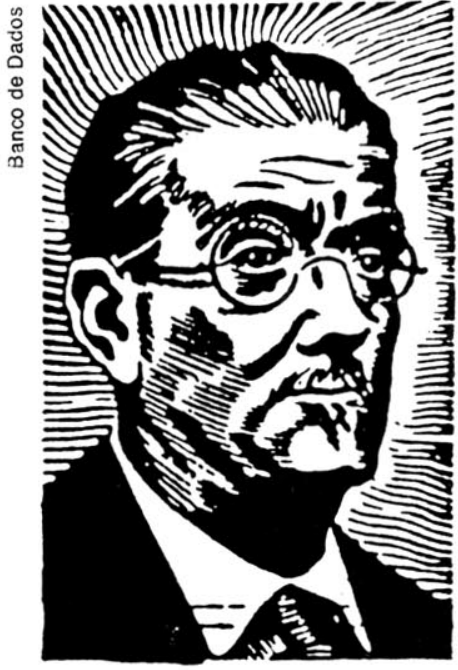

O escritor irlandês James Joyce vém lembrar o início de sua "sintética" de Valéry: "Enumerar los hechos de la vida de Valéry es ignorar a Valéry, es no aludir siquiera a Paul Valéry. Los hechos, para él, solo valen como estimulantes del pensamiento: el pensamiento, para él, solo vale en cuanto lo podemos observar; la observación de esa observación también le interesa...". Mas, ao mesmo tempo, Borges não cai no antibiografismo, tão comum na época, em oposição à onda de biografismo estreito, e, tratando de Valéry, não deixa de transmitir alguns dados concretos, certamente necessários como "estimulantes del pensamiento", numa atitude semelhante à que seria assumida anos mais tarde por Roland Barthes, com os seus "biografemas".

A subseção sobre "vida literária" não se detém nas frivolidades e sensaborias freqüentemente designadas por esta expressão, mas aproveita o pretexto para desenvolver algum pensamento sobre literatura ou dar a impressão que lhe causou algo noticiado na imprensa. Assim, no número de 27 de novembro de 1936, registra a declaração de Theodore Dreiser de que o cinema estava em vias de anular o romance. E o fato de registrá-la simplesmente, sem acrescentar a sua própria opinião, tem algo de esconde-esconde com o leitor.

Realmente, escrevendo sobre este livro, dá vontade de seguir à risca o exemplo de Borges e transcrever as suas tão lúcidas formulações. Mas o problema está em que se torna difícil escolher o essencial, como ele fazia em relação às obras que lia. Tudo parece importante. Mesmo assim, aí vai um trecho, a propósito de um livro sobre Kipling: "El tiempo acumula experiencias sobre el artista, como sobre todos los hombres. A fuerza de omisiones y de énfasis, de olvido y de memoria, éste combina algunas de ellas y elabora ast la obra de arte. Después la crttica desteje laboriosamente la obra y recupera (o finge recuperar) la desordenada realidad que lo motivo. Repone el caos primordial, es decir'".

É verdade que, resenhando livros então recém-publicados, ele se ocupou de muitas obras que hoje em dia não nos dizem nada. Mas, por mais insignificante que seja o livro abordado, Borges sempre encontra um meio de dizer coisas muito agudas. O objeto pode ter desaparecido na insignificância, mas o comentário perdura.

A agilidade de sua escrita, a leveza de toque com que ele aborda os temas mais eruditos, tornou possível levar para as páginas daquela revista feminina resenhas como a dedicada a Men of Mathematics, de E. T. Bell, "una historia de los matematicos europeos", na qual aponta o defeito do apego à ordem cronologica. Esta lhe parece muito enganadora: "Es el caso de los atolondrados cursos elementales de historia de la metaflsica: para exponer el idealismo a los auditores, les presentan primero la inconcebible doctrina de Platón y, casi al fin, el limpido sistema de Berkeley, que si historicamente es posterior, logicamente es previo...".

Como se vê, sua atitude ê bem iconoclasta. É a postura de um fruidor impenitente de textos, que por isso mesmo se dá o direito de rejeitar o que não o atrai tanto. Coragem de dizer as opiniōes de modo desabusado? Gosto pelo paradoxo e pelo chocante? Uma coisa e outra? Não importa. Mas, embora confesse não ter conseguido ler nem Madame Bovary nem Os Irmãos Karamazov, ocupa-se de livros que já surgiam superados.

As suas idiossincrasias estão bem presentes em tudo o que escrevia. Por exemplo, é bem implacável o seu veredicto sobre Poe, cuja teoria poética seria "harto superior $a$ su práctica" e cujos poemas como "O Corvo", "Os Sinos" e "Annabel Lee" estariam relegados "al submundo (sin duda menos infernal que molesto) de la declamación". (Não se esqueça de que isto foi escrito na época dos recitais de declamação de Berta Singerman - com os seus vestidos em asas de morcego e seus gestos patéticos -, que eram coqueluche não só em Buenos Aires, mas também no Rio de Janeiro e em São Paulo.) Lembrando que assim mesmo ele foi autor de "nueve o diez cuentos indiscutibles", que inventou o gênero policial e que Paul Valêry lhe devia tanto, conclui: "Todo ello basta para justificación de sua gloria, pese a las redundancias y languideces que sufren cada página".

Tratando de um caso de utilização de psicanálise na abordagem de textos literários (a biografia crítica de Heine por Louis Untermeyer), chega a censurar no livro o "abundante manejo de la jerigonza peculiar del doctor Segismundo Freud"'. A par da graça e encanto de sua prosa, a injustiça de alguns de seus jú́zos é praticamente uma constante. Assim, tratando de Enjoyment of Laughter, de Max Eastman, afirma que "el autor aniquila las muy aniquilables teorias de Bergson y de Freud"', quando seria muito mais justo afirmar que na extensa obra de Freud sobre o chiste há uma contribuição muito séria ao conhecimento dos mecanismos da psique, embora ele não traga muito para uma teoria do humor e do cômico, a não ser um vasto material ligado a esses temas.

No decorrer de todo o livro, percebe-se a preocupação de Borges com o moderno, 


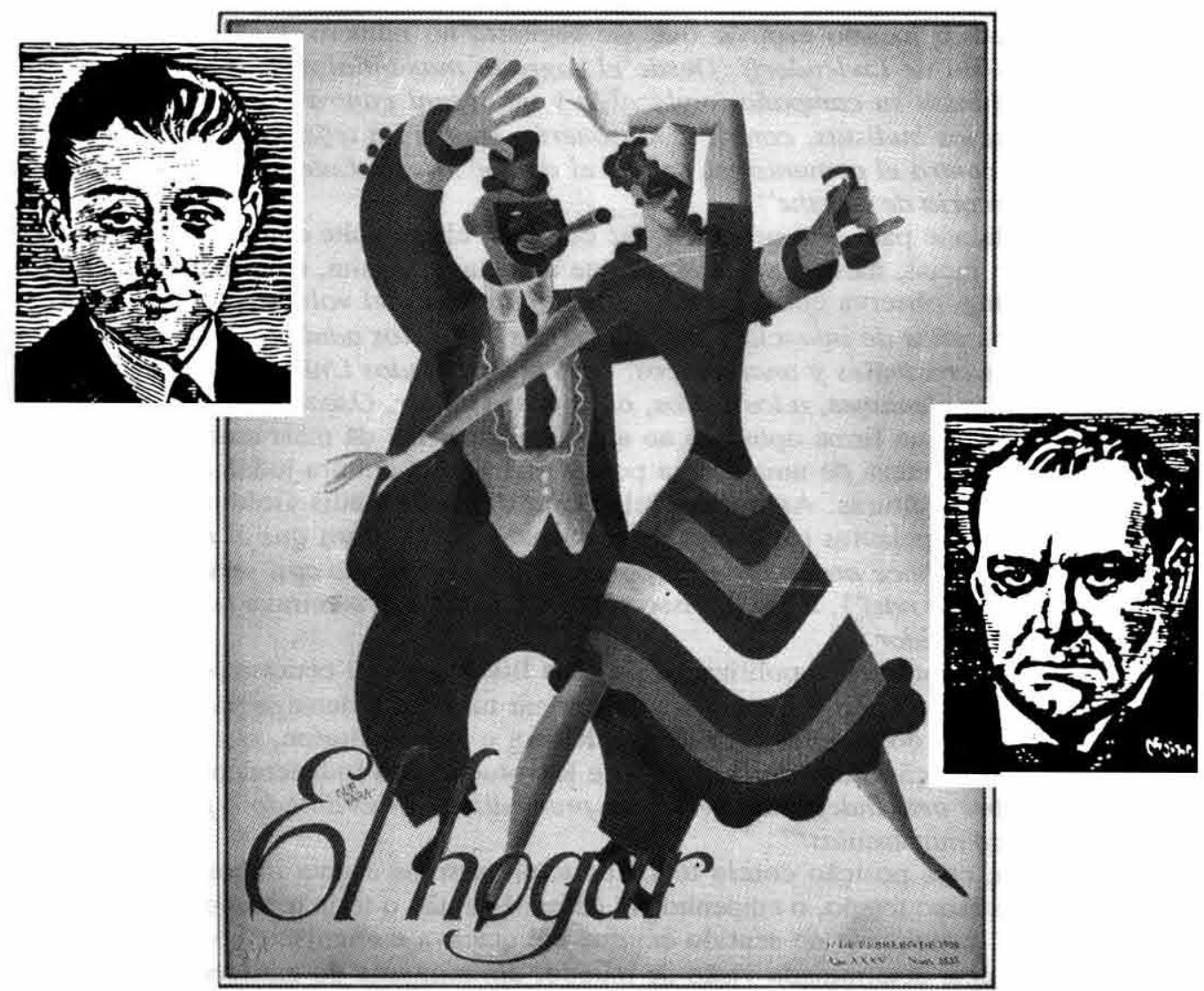

mas ao mesmo tempo, ele, que fora um dos principais representantes do ultraísmo, expressa agora um cansaço em relação às vanguardas. Eis, por exemplo, o que escreveu em 1937: "Una de las coqueterías literarias de nuestro tiempo es la metodica y ansiosa elaboración de obras de aparencia cabtica. Simular el desorden, construir dificilmente un caos, usar la inteligencia para obtener los efectos de la casualidad, esa fue, en su momento, la obra de Mallarmé y de James Joyce. La quinta década de los Cantos de Pound, que acaba de salir en Londres, continua esa extraña tradición".

E a propósito do manifesto de Andre Breton e Diego Rivera em 1938, lembra que, uns vinte anos antes, "esos autoritarios documentos renovaban el arte, aboltan la pontuación, evitaban la ortografla y a menudo lograban el solecismo"'.

Mas, ao mesmo tempo, tem posições bem avançadas. Por exemplo, a propósito de The Wild Palms, de Faulkner, lamenta a inexistência, em 1939, de uma história das formas do romance, uma verdadeira morfologia desse gênero.

Como não podia deixar de acontecer, os textos borgianos de El Hogar estão muito marcados pelo momento histórico. A tensão daqueles anos, às vésperas da Segunda Guerra Mundial, irrompe nos textos literários, era impossível ficar distante. Mas Borges se empenha a fundo na tentativa de manter a lucidez, de não se deixar arrastar pelas paixões desencadeadas. Ele que tivera suas simpatias pela Revolução Russa e chegara a escrever poemas revolucionários não se deixa arrastar pelas ilusões das esquerdas da época. Sua preocupação em não se envolver é evidente na abordagem que faz de duas obras sobre Rimbaud, que acabavam de sair em Paris: uma de Daniel-Rops "estuda" Rimbaud (aspas de Borges) de um ponto de vista católico; a outra, de Gauclère e Etiemble, "desde el fastidioso punto de vista del materialismo dialéctico". E ambos, segundo ele, resultam num fracasso total.

Imbuído do mesmo espírito, aponta para os extremos ridículos a que chegara o culto ao chefe supremo, tanto em Berlim como em Moscou.

Sua posição é declaradamente antitotalitária, pela discussão ampla de tudo, contra os particularismos alienantes que levam à desinformação.

Em mais de uma ocasião, volta-se com vigor contra o anti-semitismo então em ascensão em muitos países. Desmascarando as atrocidades do nazismo, ele na realidade estava assumindo uma posição muito importante na Argentina, naquele momento de tantos perigos. Para alguém que era tão apegado à lucidez, à busca da clareza e objetividade, só podia ser muito doloroso ler um livro didático alemão como o assinado por Elvira Bauer, no qual as crianças eram iniciadas no anti-semitismo e incitadas a agir contra os

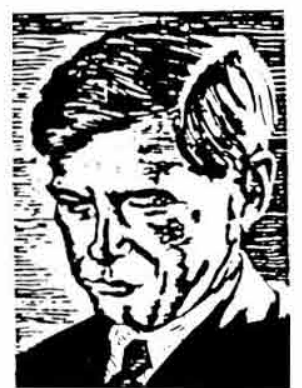

Ao centro, capa do semanário portenho "El Hogar", de 17 de fevereiro de 1939, no qual Borges publicava suas resenhas; autores por ele resenhados, acima, da esq. para dir.: Franz Kafka, Olaf Stapledon e Hilaire Belloc (ao lado) 

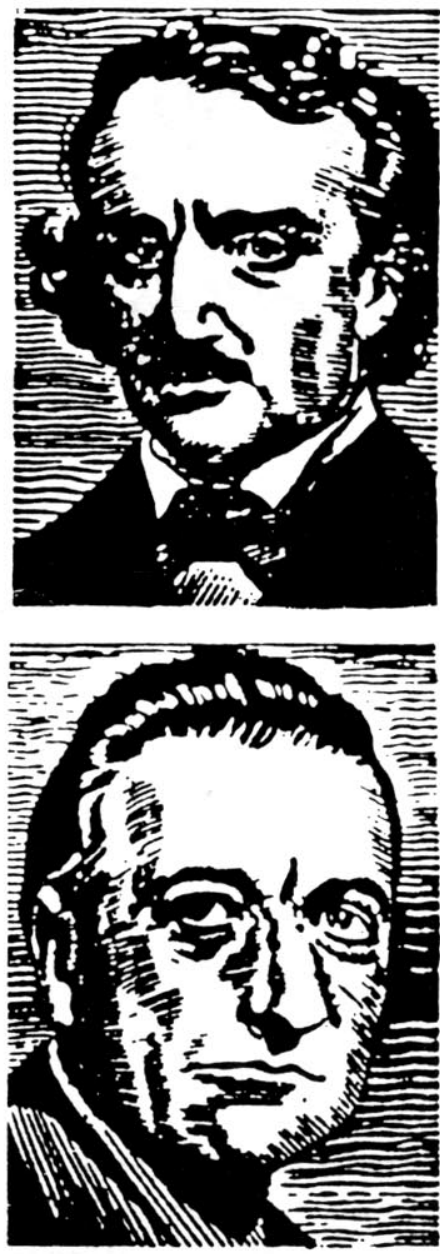

O norte-americano Edgar Allan

Poe, em cima; Jules Romains,

abaixo judeus. E é com o mesmo espírito que ele registra, no número de 3 de setembro de 1937: 'La revista de Ludendorff 'Desde el sagrado manantial de la fuerza alemana' prosigue en Munich su campaña implacable y quincenal contra los judios, contra el papado, contra los budistas, contra la masonerí, contra los teósofos, contra la Sociedad de Jesús, contra el comunismo, contra el doctor Martin Lutero, contra Inglaterra y contra la memoria de Goethe".

Sua sensibilidade para este problema faz com que ele se volte contra o aparecimento do preconceito racial, mesmo nos autores que apreciava. Assim, em relação à autobiografia de Kipling, observa que "los más gratos capttulos del volumen son los que corresponden a los años de infancia y juventud. (Los otros, los adultos, están contaminados de odios inverostmiles y anacrónicos: odio a los Estados Unidos, a los irlandeses, a los boers, a los alemanes, a los judios, al espectro de Mr. Oscar Wilde.)"”

Justamente esta sua firme oposição ao anti-semitismo lhe dá mais autoridade para se voltar contra a estreiteza de uma defesa pura e simples da cultura judaica, colocada em oposição a outras culturas. Assim, em relação ao livro de Louis Golding, The Jewish Problem, encontra palavras candentes de condenação: "Declara que el racismo es disparatado, pero no hace otra cosa que oponer, con una simetrla casi servil, un racismo israelita al racismo nazi"'. E ele diz isso sobre um autor que admirava por causa de seu romance $\boldsymbol{O}$ Perseguidor.

A sua posição contrária à politização da obra literária e seu ceticismo em relação ao materialismo dialético não o impediram de criticar também a demagogia anti-soviética. Assim, a propósito do manifesto de Diego Rivera e André Breton, que propugnava a fundação da Federação Internacional da Arte Revolucionária Independente (F.I.A.R.I.), exclama: "Pobre arte independiente el que premeditan, subordinado a pedanterlas de comité y a cinco mayúsculas!".

Sem dúvida, esta posição contra todos os totalitarismos estava impregnada de lucidez. Mas, ao mesmo tempo, o empenho em defendê-la não o teria tornado, em certa medida, militante, justamente no sentido em que ele atacava o engajamento do intelectual, a fidelidade a uma determinada visão de mundo, um militante do antiideologismo? Sua oposição a uma arte ligada à esquerda, a uma atitude ostensiva e declaratória, deve ter contribuído para a sua afirmação, em 1938, a propósito do Guide to the Philosophy of Morals and Politics, de E. M. Jod, de que "cabe sospechar que no se ha producido hasta ahora un arte comunista". Passados os anos, torna-se claro que o problema não estava no fato de haver ou não uma "arte comunista", mas parece estranho que Borges se tenha mantido alheio à grande reviravolta artística na Rússia, no período que se seguiu à Revolução. Segundo parece, sua aversão ao maniqueísmo, às visões em preto e branco, fez com que visse no cinema soviético das décadas de 1920 e 30 unicamente aquela oposição entre bons e maus. Hoje em dia, com o distanciamento no tempo, torna-se mais fácil constatar o que subsiste de grande e forte naqueles filmes, apesar do simplismo nas oposições de contrários. E como foi possível a Borges, tão apegado à poesia no mundo, deixar de ver, mesmo com a escassez de informações, a grandeza de um poema como "Os Doze" de Blok ou os versos impressionantes de Maiakóvski? Isto para não falar de outros, então menos acessíveis. Não seria realmente um problema de tradução?

Pelo menos num caso, porêm, o mundo surgido com a Revolução Russa encontra acolhida na obra de Borges. Realmente, este fino apreciador de prosa não poderia ficar indiferente à obra de Isaac Bábel. A "biografia sintética" deste foi traçada com todo o carinho e apuro. E embora fosse tão precária na época a comunicação com aquele mundo, o autor soviético aparece ali em toda a sua grandeza.

Este livro se torna ainda mais impressionante quando pensamos nas vicissitudes pessoais que seu autor viveu, sobretudo em 1938, quando morreu o seu pai e ele mesmo foi vítima de um terrível acidente, que o deixou por algum tempo com a vida em perigo, porém mesmo nestas circunstâncias a interrupção de suas colaborações a El Hogar foi mínima.

Enfim, temos com os Textos Cautivos um livro para ler e reler continuamente. E além de ler, olhar, pois ele se faz acompanhar de uma iconografia de época muito bem escolhida e a própria capa traz um ilustrativo desenho de Guevara. Percebe-se melhor o impacto que esses textos deveriam causar, quando se vê sua inserção na página, ao lado de anúncios de Ovomaltine ou Anglo.

Se Emir Rodríguez Monegal nos deixou obras importantes sobre seu amigo, que morreria sete meses depois dele, este livro, nascido certamente de uma obsessão por aquelas páginas de El Hogar, nos traz um Borges fascinante em sua multiplicidade e clarividência. 